\title{
SATELLITE IMAGERY-BASED MONITORING OF ENVIRONMETAL DAMAGE IN THE SYRIAN CONFLICT
}

DOI: http://dx.doi.org/10.18509/GBP.2020.19

UDC: 504.61:355.01]:528.88(569.1)

\author{
Tatjana Jovanovska ${ }^{1 *}$ \\ Gordana Kaplan ${ }^{2}$ \\ Toni Mileski ${ }^{1}$ \\ ${ }^{1}$ Ss. Kiril and Metodij University, Skopje, Institute for Security, Defense and Peace, Skopje, \\ North Macedonia \\ ${ }^{2}$ Earth and Space Sciences Institute, Eskisehir Technical University, Eskisehir, Turkey
}

\begin{abstract}
The conflict in Syria is one of the largest war conflict in the 21st century. Since 1960s, remote sensing satellite imagery has played a significant role in military operations by providing information, and in the last few decades, has been used to investigate the environmental damages in conflict areas. The moderate resolution of the Landsat constellation, provides us rich set of imagery all over the World.

The aim of this study is to investigate the environmental change, and its influence over the urban ecological security in conflict areas. Since our goal is to determine the environmental damage caused from the war conflict, we analyze two satellite images over the most affected areas in the conflict in Syria, one before the beginning and one after the end of the conflict. As the war initially started in 2011, two Landsat images, from 2011 and 2019 have been processed and classified in several land cover classes.

The results showed drastic decrease of the vegetated areas, which affects the general ecological state of the environment, or more than $70 \%$ decrease in the green areas, and more than $30 \%$ of the arable areas. The conflict in Syria and the subsequent absence of the preservation of forests and natural vegetation by the relevant authorities has played an important negative role in land cover change.
\end{abstract}

Keywords: Environmental Security, Syrian War, Remote Sensing, Environmental Damage.

\section{INTRODUCTION}

The term environmental security first appeared as a serious concept in safety studies as a result of some interrelated developments in the 1960s. NATO continues to put environmental security on the priority list [1]. Environmental security examines threats posed by environmental events and trends to individuals, communities or nations. There is widespread agreement that environmental degradation and change can endanger security where the term "security" may be of national, international or human security type [2]. International security is most affected by this situation as it can affect both national and international security. While environmental degradation and climate change can contribute to the close co-operation of states, they can also indirectly contribute to conflict. Strictly speaking, it can weaken the national security of the state in many ways. Given the aim of environmental security and the purposes of remote sensing and geoformation sciences, it can be concluded that these sciences are closely linked [1]. This 
is evidenced by the many researches done on the topic of environmental security using remote sensing methods [3-6].

Also, Jaafar and Woertz [7] did research on agriculture as a source of ISIS resources using geoinfomration systems (GIS) and remote sensing, observing the agricultural areas in Syria and Iraq for the period 2014-2015. Giovannetti and Perra [8] use night time satellite imagery to analyze the economic consequences of the war in Syria. The results indicate that the nightlights of Syria after the conflict has decreased by more than $64 \%$.

Lubin and Saleem [9] in their research use images from the Landsat satellite to assess the damage caused by the civil war in Syria between 2011 and 2017 in the city of Aleppo. Results show that the city of Aleppo was destroyed between $45-57 \%$.

Taking into account the aforementioned researches, we get a clear picture of the application of remote sensing in conflict regions. Undoubtedly, the results are as significant as the present and future situation of Syria. However, none of these studies investigates the ecological security and environmental degradation caused by the conflict in Syria. For that purpose, in this study, we use two Landsat images, before and after the conflict in Syria in one of the biggest areas in Syria, Aleppo.

\section{METHODS}

\section{Study Area and Data}

In order to provide a clear picture of the changes and damage to the environment from 2011 to 2018 in Syria before and after the end of the civil war, in this paper paper remote sensing methods and data are being used. The area of research was delineated by the political boundaries of the Aleppo area, which is one of the most important and most populated areas in Syria. The area to the north and northwest borders the Republic of Turkey. In the area runs part of one of the most important rivers in the Middle East region, the Euphrates. The capital of the area is the city of Aleppo. Figure 5 presents a detailed overview of the research area and is highlighted in red.

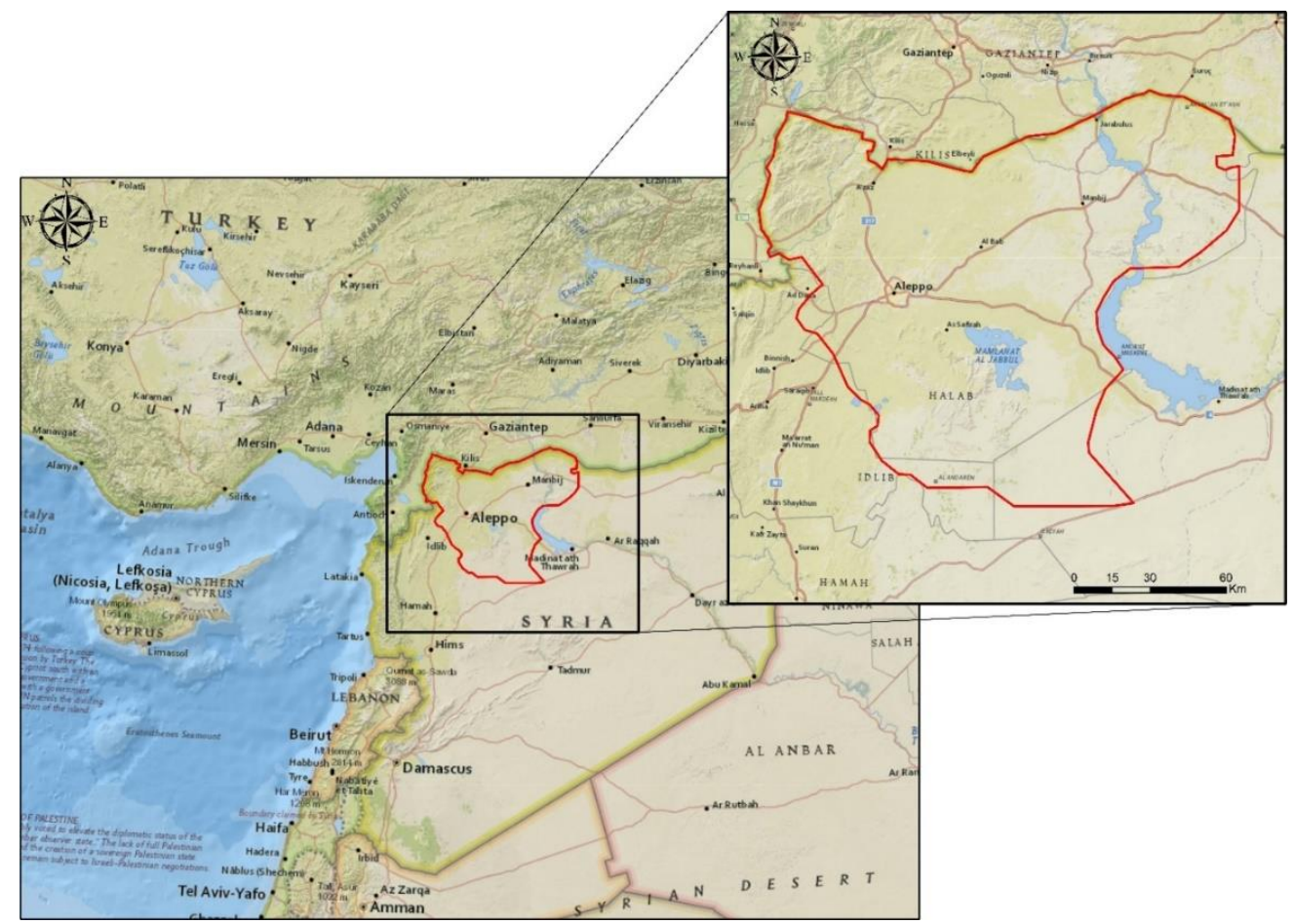

Figure 1. Study area, Aleppo, Syria 
This study used two Landsat -5 and two Landsat -8 satellite images. Details of the satellite images are given in Table 1.

In order to preserve the continuity and avoid the erroneous conclusion drawn from the time-lapse data, taking into account the phenological cycle of the environment, satellite images of the same period of the year, August, when the green surface in Syria was most developed were used in this paper. As most of the footage overlaps, particular importance was given to selecting portions of the non-cloud footage.

Table 1. Details about the satellite images used in this study

\begin{tabular}{|c|l|c|c|c|c|}
\hline & Satellite & Path/Row & Date & Cloud & Quality \\
\hline 1 & Landsat -5 & $173 / 035$ & August 2011 & $0 \%$ & 9 \\
\hline 2 & Landsat -5 & $174 / 035$ & August 2011 & $10 \%$ & 9 \\
\hline 3 & Landsat -8 & $173 / 035$ & August 2018 & $0,1 \%$ & 9 \\
\hline 4 & Landsat -8 & $174 / 035$ & August 2018 & $9 \%$ & 9 \\
\hline
\end{tabular}

\section{Methodology}

The main analysis of satellite imagery was performed using vegetation indices. Namley, with the use of the infrared part of the electromagnetic spectrum, Normalized Difference Vegetation Index (NDVI) can be calculated and the quality of the green surfaces can be determined [10].

$$
N D V I=\frac{N I R-R e d}{N I R+R e d}
$$

Using satellite imagery from the Aleppo area of 2011 and 2018, two separate vegetation maps have been produced represent the vegetation cover in the area. After preparing the maps, a statistical analysis was performed to calculate the areas of water, barren, bare and green cover. This division of surfaces is done according to the NDVI values. That is, areas with values less than zero are classified as water, areas with values between 0 and 0.2 are classified as barren, areas with values between 0.2 and 0.4 are classified as bare, while areas with values greater than 0.4 are classified as healthy, green surfaces [11].

\section{RESULTS}

From the results presented in Figure 2, it can be noticed that drastic differences occurred between the beginning and the end of the civil war, from 2011 to 2018. The differences are particularly drastic in the vicinity of Lake Al Jaboul, an area that is significant from an agricultural point of view and is one of the greenest areas in Syria. In addition to losing much of the green area, also the water area of Lake Al Jabol has decreased. In addition to the differences visible from satellite imagery, geostatistical analyzes were also performed in this study, and the analyzes of which are presented in Table 2 . Table 2 presents the differences in the studied areas between 2011 and 2018. According to the results, during the 2011 civil war, a total of 11,179 hectares were converted into empty / barren land. 


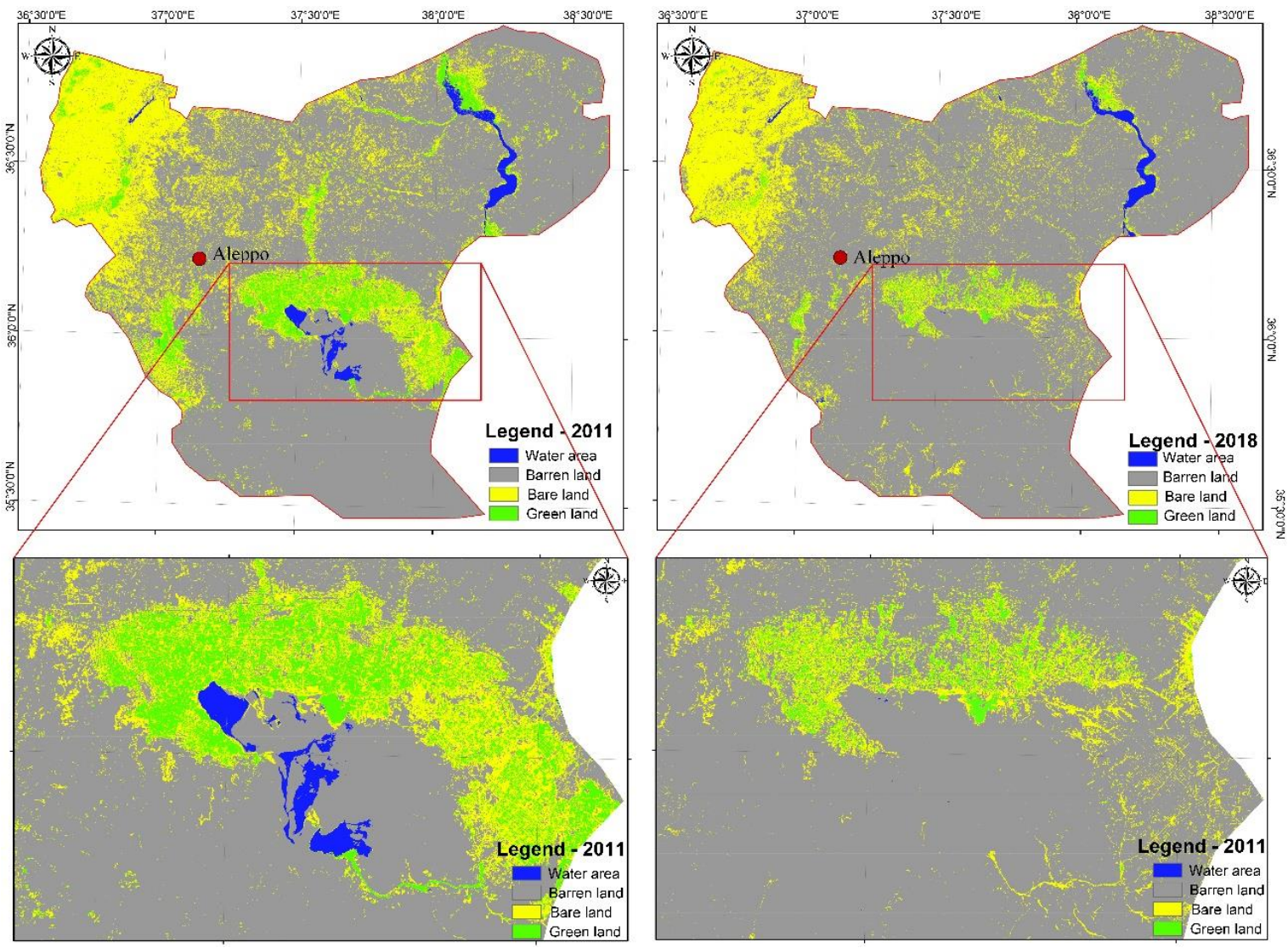

Figure 2. Results

Table 2. Aleppo land cover difference - August 2011-2018

\begin{tabular}{cc} 
Land cover & $\mathrm{km}^{2}$ \\
\hline Water & -111.8 \\
Barren & 2082.9 \\
Bare & -1293.5 \\
Green & -678.4 \\
\hline
\end{tabular}

The reasons for the decline in useful green, bare and wetlands in barren / empty land are mainly related to events related to military conflict such as; eviction, excessive use of water by terrorist organizations, mass evictions, and thus land abandonment.

\section{DISCUSSION}

In this research, special attention was given to Aleppo, as one of the most affected areas in the civil war in Syria. Using both remote sensing and GIS the changes in the vegetation cover were analyzed. The results apply to the loss of green space, but also to the loss of soil fertility as well as to wetlands.

This confirms the fact that environmental security in Syria has been disrupted as a result of the military actions from 2011 to 2018 . This fact is corroborated by the aforementioned researches which clearly stated the environmental damages, especially the green land cover, ie the arable land, and the water areas in the Aleppo area. This situation is to be expected given the large number of expatriates who have left their lands. It is also assumed that the reduction of water levels in the area is the result of terrorist acts, halting of water flows to Aleppo, uncontrolled use of water reservoirs by ISIS, etc. 
Also, the results can be supported with other another research where it was concluded that larg agricultural areas have been abandoned and thus the agricultural productivity has decreased by $50 \%$. Abandoned arable land is an indication that civil war is the cause of immigration, death and trauma. The results also explain the great damage caused by the war.

\section{CONCLUSION}

Finally, in the concluding observations of this research, we give a brief overview of its three-part content, summarizing the main issues and issues we dealt with. We have attempted to structure a more complex picture of the situation in Syria between 2011 and 2018 (occasionally including pre-war country data), including some important aspects of Syria's problems, above all the environmental problem security before and during the war. The damage to human casualties as well as to refugees is enormous. But there are also huge damages to the country's environmental security - the whole picture of the country's environment has changed drastically. Although these issues have already been raised, it is time for more aggressive and larger steps towards protecting and promoting the environment in Syria, which is necessary for the Syrian population, but it is also necessary for the entire planet - this has long stopped to be the problem of a state and to grow into a global problem that requires global commitment and investment in its solutions.

It is precisely the raising of global awareness of the importance of the aspect of environmental security in Syria, in addition to analyzing and recording the damages that resulted (and still arise) from the war, and one of the main goals of our research.

\section{REFERENCES}

[1] Coskun, H.G., U. Alganci, and G. Usta, The role of remote sensing and GIS for security, in Integration of Information for Environmental Security. 2008, Springer. p. 323-337.

[2] Pugh, J., Retos y oportunidades de los conflictos humanos y la transformación ambiental en las montañas de Ecuador. Pirineos, 2008. 163: p. 63-75.

[3] Mileski, T., Kaplan, G., Urban Heat Island Effects Over the Urban Security: Case Study of the City of Skopje. URBAN SECURITY Enhancing Security in an Urbanized World, 2019.

[4] Kaplan, G.A., U; Yigit Avdan, Z; Jovanovska, T;, Remote Sensing Techniques for Monitoring Shared International Waters; Study Case - Dojran Lake. International Disaster and Resilience Congress, 2019.

[5] Li, X., et al., Intercalibration between DMSP/OLS and VIIRS night-time light images to evaluate city light dynamics of Syria's major human settlement during Syrian Civil War. International Journal of Remote Sensing, 2017. 38(21): p. 5934-5951.

[6] Abdo, H.G., Impacts of war in Syria on vegetation dynamics and erosion risks in Safita area, Tartous, Syria. Regional Environmental Change, 2018. 18(6): p. 1707-1719.

[7] Jaafar, H.H. and E. Woertz, Agriculture as a funding source of ISIS: A GIS and remote sensing analysis. Food Policy, 2016. 64: p. 14-25.

[8] Giovannetti, G. and E. Perra, Syria in the Dark: Estimating the Economic Consequences of the Civil War through Satellite-Derived Night Time Lights. 2019, Universita'degli Studi di Firenze, Dipartimento di Scienze per l'Economia e ....

[9] Lubin, A. and A. Saleem, Remote sensing-based mapping of the destruction to Aleppo during the Syrian Civil War between 2011 and 2017. Applied geography, 2019. 108: p. 30-38.

[10] Rouse, J., et al., Monitoring vegetation systems in the Great Plains with ERTS. NASA special publication, 1974. 351: p. 309. 
[11] Avdan, U. and G. Jovanovska, Algorithm for automated mapping of land surface temperature using LANDSAT 8 satellite data. Journal of Sensors, 2016. 2016. 